\title{
Professional and personal readiness of a teacher as a component of an inclusive culture
}

\author{
E.S. Slusareva ${ }^{1 *}$, and $A . V$. Dontsov $^{2}$ \\ ${ }^{1}$ State budgetary educational institution of higher education «Stavropol state pedagogical Institute», \\ Stavropol, Russia \\ ${ }^{2}$ State budgetary educational institution of higher education «Stavropol state pedagogical Institute», \\ Stavropol, Russia
}

\begin{abstract}
Currently, inclusive education is becoming widespread as equal access to education for all children, regardless of starting opportunities. In this regard, an important task of an educational organization is the formation of an inclusive culture that allows building subject-subject relations between all participants in educational relations based on humanism and the acceptance of the value of each child. The professional and personal readiness of the teacher is a component of the inclusive culture of the educational organization and the inclusive culture of the personality of the teacher.
\end{abstract}

\section{A problem statement}

One of the strategic directions of the state policy in the field of education in the Russian Federation is to ensure the right of every child to education, regardless of his psychophysiological capabilities. In this regard, the issues related to the organization of joint (inclusive) education of children with different starting capabilities acquire particular relevance: regulatory support of this process; architectural design of the premises, ensuring accessibility and safety; content and teaching methods, teacher's readiness to interact with children with special educational and communication needs, etc. In the domestic education system, these problems are considered in connection with the provision of such an inclusive educational environment, the key principle in the construction of which is the principle of compliance: the child's special educational needs with his capabilities and the creation of special educational conditions that correspond to the needs and capabilities of both a child with disabilities and other categories children (naturalness of educational influences to the needs and capabilities of the child).

In foreign studies, the problems of inclusive education are considered in such definitions as inclusive culture and inclusive practice, which reflect both a fundamental understanding of inclusion - an interdisciplinary phenomenon and a special philosophy of accepting differences, and applied - organizational, methodological, psychological aspects of ensuring inclusive educational practice.

* Corresponding author: ipcs-profped@yandex.ru 
The formation of an inclusive culture in an educational organization is considered by researchers and practitioners as a task, the solution of which lies at the basis of inclusion and includes the acceptance of the values of respect for diversity, tolerance for differences, cooperation, encouragement of the achievements of everyone and the creation of an inclusive community on their basis (T. Boot, M. Ainscoe) [5]. The main role in the formation of an inclusive culture is assigned to the teaching staff in the educational organization, which is considered as a collective subject of the educational process and the bearer of values, traditions, attitudes. In this regard, it is very relevant to consider the problem of the teacher's professional and personal readiness as a component of the inclusive culture of the educational organization and the inclusive culture of the teacher's personality.

\subsection{The objective of the work}

In foreign studies, inclusive culture presupposes the creation of a psychologically safe environment, partnerships between participants in the educational process, recognition of equal opportunities for students, the cultivation of personality-oriented relationships, the inclusion of all students in all aspects of school life, and the minimization of all types of discrimination. The formation of an inclusive culture in an educational organization is considered by researchers and practitioners as a task, the solution of which lies at the basis of inclusion and includes the acceptance of the values of respect for diversity, tolerance for differences, cooperation, encouragement of the achievements of everyone and the creation of an inclusive community on their basis (T. But, M. Ainscoe) [5].

Domestic researchers (T.P. Dmitrieva and her colleagues) consider inclusive culture in connection with the school community's acceptance of the values of inclusion, understanding the need to support individuality, and realizing the need for development of each of its participants, regardless of the "starting" opportunities. An educational institution that has its own "way", visible relations of support and participation, an order of life that one does not want to violate, always attracts active, creative employees capable of professional development, parents interested in active interaction [8].

N.V. Starovoit, relying on the "iceberg model", proposes to consider the inclusive culture of the school, in which there is a "surface" and "underwater" part [19]. Above-water part of an inclusive educational culture is both an adaptive safe-developing educational space, and content-methodological support aimed at meeting the special educational needs of students, and human resources, etc. It should be noted that the "above-water part" of inclusive culture is the subject of consideration in many research works (S.V. Alekhina, T.D. Dmitrieva, V.V. Khitryuk, etc.) [2, 8, 23].

The "underwater part" of inclusive culture is associated with deep phenomena based on the acceptance of the philosophy of inclusive education, the value of each subject of educational relations. This is the most difficult part of inclusive culture to form, associated with the acceptance of the values of inclusion both in education and in society.

It follows that the inclusive culture of the school has a complex structure: external (adapted accessible environment, content and teaching methods, etc.) and internal (a system of ideas, rules, attitudes, values and behaviors common to the group and which are a condition for the stability of the group) [3].

Considering the local environment of a particular educational organization, A.I. Polyansky et al. note that the internal (hidden) part of inclusive culture is expressed in the practices of non-verbal communication, in the rules of behavior and social norms followed by teachers, students and parents [15].

Summarizing the above approaches, O.V. Solovyova defines the inclusive culture of an educational organization as a special philosophy and a comfortable educational 
environment corresponding to it, which implies the full and successful integration of diverse people into educational and extracurricular activities and reflects a climate in which respect, equality and positive recognition of differences are cultivated [18].

Based on the views of Ye.V. Bondarevskaya about pedagogical culture, we define inclusive culture as an essential characteristic of the environment, way of life, a feature of the pedagogical system, which reflects the process of its movement towards a new qualitative state [4].

We find a similar position in V.V. Khitryuk in which inclusive culture is considered as a component of professional and pedagogical culture, and is defined as an integrative personal quality that contributes to the creation and development of the values and technologies of inclusive education, integrating the system of knowledge, skills, social, personal and professional competencies that allow the teacher to work effectively in conditions inclusive education, to determine the optimal conditions for the development of each child [22].

Inclusive culture in the structure of the educational environment reflects the degree of development of a teacher - a carrier of a new type of pedagogical activity, corresponding to the situation of mastering and practical implementation of the ideas of inclusive, personality-oriented education. The professional and personal readiness of a teacher is a necessary component of familiarizing a person with a widely understood culture, which acts as the highest manifestation of human education and professional competence.

Moreover, as noted by V.Z. Cantor, knowledge, skills and abilities of teachers of general education should not duplicate the training of specialists in special (defectological) education. A specialist in inclusive education can be a teacher of an absolutely new type, not reducible to the typical "sum" of the current teachers of a mass school and a teacherdefectologist [9].

Interesting are the statements of G. Feuser regarding the training of teaching staff capable of working in an inclusive school. The German scientist rightly argues that it is impossible to prepare teachers for inclusive education through "specialization in inclusion". Professional pedagogical education should itself be organized according to the principle of inclusion, on the general educational content in active forms of professional educational activity. This is a new educational culture and it can only be appropriated from the side of its "subjective appropriation" [21].

It is the subjectivity of the teacher that presupposes an attitude towards the child as a value in itself and as a subject of his own educational activity and the attitude of the teacher towards himself as a subject of his own pedagogical activity.

In the system of inclusive education, the result of the development of the subjectivity of all members of the community is polysubjective interaction in the community "teacherstudents" (I.V. Vachkov) [6]. In such interaction, the professional characteristics of the teacher, reflecting his readiness, attitudes and needs, become components that largely determine the effectiveness of inclusive education. This is also connected with the special role of the teacher as a new significant adult at the initial stage of school education.

Polysubject interaction is a form of direct interaction of subjects with each other, which is capable of generating their mutual conditionality, a special degree of closeness of relations, the most favorable conditions for development and is characterized by a special type of community - a polysubject. The polysubject is understood as an integral dynamic psychological formation reflecting the phenomenon of the unity of development of subjects who are in subject-subject relations. The essence of the polysubject is manifested in the ability for creative activity, for awareness of the system of relations between subjects, for the formation of a common semantic space, as well as in the ability to transform the world around and oneself, the ability to act as an integral subject, developing subject-subject relationships with other communities. 
In the works of I.V. Vachkov identified the following types of interaction and the corresponding types of communities [7]:

1) semi-subject interaction - being specific in relation to the subject-subject interaction, it can generate two types of community: the polysubject of communication and the universal polysubject;

2) activity-value interaction as one of the types of subject-subject interaction generates a corporate collective subject;

3 ) the possibility of the appearance of an atomic collective subject provides a subjectobject level of interaction;

4) at the lowest level - a set of pre-subjects that provide such a type of interaction as pre-subject or subject-alienated.

The criterion for such a typology is the attribution of subjective value to oneself and another person: from the lack of value of oneself and a partner (pre-subject interaction) to the level (polysubjective interaction), when each participant "returns" to the other his reflected subjectivity" (V.A. Petrovsky) [14] and gets the opportunity at a new round of interaction to act as a subject in relation to his own subjectivity (in its reflected form).

At the same time, I.V. Vachkov notes that in an inclusive educational environment it is possible for a "teacher-student" community to exist, which does not possess the quality of semi-subjectivity, which can manifest itself in the following strategies: manipulation of the teacher by students; pursuing the same goals, but these are not development goals; pursuit of the same goals - development goals, but the community is in the early stages of its formation. Such communities are more common in an inclusive educational environment than polysubjects [6].

The same idea can be traced in a number of studies, which note the difficulties of teachers in the implementation of the dialogue, since the "mass" teacher for the most part does not know how to restructure his activities on the basis of a dialogical approach, which requires great skill of the teacher, high time and neuropsychic costs. Often, teachers involved in inclusive educational practice shift the center of responsibility from their own professional actions outside to parents, methodological support of the educational process, which may be due to a lack of successful experience in teaching and raising children with disabilities or unwillingness to take responsibility for the quality of teaching children with preserved and impaired development $[2,9,11,12,16]$.

Thus, the teacher's readiness is a leading condition [11, 16], a factor [2] for the effective implementation of inclusive educational practice, a stage in the formation of an inclusive culture of a teacher and the educational organization as a whole [10,22].

The relevance of the study made it possible to set the goal of the study - to theoretically substantiate and experimentally investigate the professional and personal readiness of teachers as a component of an inclusive culture.

The study was carried out on the basis of two educational organizations: a school that has been implementing inclusive culture and practice for more than 15 years (Municipal Budgetary Educational Institution Secondary School No. 21), and a school that is on the path of forming an inclusive culture and whose experience is 7 years (Municipal Budgetary Educational Institution Secondary School No. 12).

The tasks of the research were:

1. To study the state of professional and personal readiness of teachers as a component of an inclusive culture.

2. To reveal among teachers the presence of barriers of interaction and the degree of their severity.

3. To study the relationship between the components of professional and personal readiness. 
To realize the goal of empirical research, we used the method of psychological diagnostics of teachers' readiness to implement inclusive educational practice, including a questionnaire of knowledge formation in the field of inclusive education; questionnaire of the formation of skills in the implementation of inclusive education; questionnaire "Psychological barriers of teachers in the process of interaction in an inclusive educational environment" [17].

The data obtained were presented by us in the form of primary mathematical statistics: absolute and relative indicators.

In modern research, the teacher's readiness is considered in the aspect of professional and psychological readiness [2,13], inclusive readiness as a component of the general professional and pedagogical readiness [23], the teacher's professional and personal readiness [24], etc.

I.M. Yakovleva notes that the preparation of teachers for the implementation of inclusive educational practice is mainly aimed at the formation of theoretical readiness: knowledge about the clinical and psychological characteristics of children and adolescents with different variants of deviant development, special educational needs due to these characteristics, special educational conditions necessary to meet educational and the communication needs of children. However, the professional and personal readiness of the teacher, which includes the professional and humanistic orientation of the personality, professional and personal qualities and skills, is considered to a much lesser extent [24].

The professional-humanistic orientation of the personality is manifested in the teacher's awareness of the humanistic values of professional activity, satisfaction with it, purposefulness in mastering professional skills, the effectiveness and activity of the individual in achieving the humanistic goals and objectives of upbringing and teaching children. To the professional and personal qualities and skills of I.M. Yakovleva attributes: mercy, empathy, tolerance, pedagogical optimism, a high level of regulation of their activities, etc.

In our opinion, in addition to these general pedagogical professionally important personality traits, it is necessary to single out as a center-forming special ability - the ability to recognize and overcome emerging psychological barriers, which can both destructively affect the ongoing joint activity, and mobilize the resources of the teacher and bring him to a higher level of professional and personal development.

\section{Materials and the results of the research}

We find the division of our research position in the works of S.V. Alekhina, who considers the following as one of the recommendations to the teacher: "identifying barriers in order to, if not eliminate, then at least figure out how to overcome them is one of the most important tasks facing the school on the way to building an inclusive environment ... whether it is necessary to find out the opinion of teachers about the possible difficulties of learning and socialization of their students becomes obvious if overcoming is considered as a key word. Many teachers see difficulties, while only a few are ready to overcome them creatively, or even systematically "[1].

The use of the methods of theoretical analysis and the method of expert assessments allowed us to identify the following groups of psychological barriers that arise for teachers as subjects of interaction in an inclusive educational environment:

Group 1 - psychological and cognitive barriers:

- are manifested in the deficit or lack of formation of teachers' ideas about the special educational needs of children of different nosological groups; inability to transfer existing knowledge into the practice of joint education of different groups of children, etc.; 
- associated with the lack of development of practical skills for the implementation of inclusive educational practice (analytical, predictive, communicative, etc.). Often, the knowledge that teachers receive through the development of professional retraining and advanced training programs is not reflected in practical experience, especially when it comes to interacting with children with severe and multiple developmental disabilities.

Group 2 - emotional barriers: the barrier of self-doubt; mental tension barrier (anxiety, inability to initiate contact with a child with developmental disorders); fear barrier; a barrier of shame and guilt arising from embarrassment for oneself or another.

Group 3 - communication barriers or communication barriers: semantic, linguistic, logical, phonemic barriers affecting the initiation, content, semantic content of the teacher's communication with children.

We find a reflection of our point of view in the studies of O.Yu. Litvintseva, E.S. Fominykh, and others, who distinguish two groups of barriers that manifest themselves in an inclusive educational environment: social barriers that manifest themselves in a negative attitude towards students with disabilities and psychological barriers caused by the unwillingness to include the subjects of the educational process at the psychological level $[12,20]$. Psychological barriers of teachers are associated with the problems of attitude towards a student with disabilities and his emotional acceptance; as a result - insufficient acceptance of the very idea of inclusion, difficulties in building an inclusive culture in an educational organization due to the influence of stereotypes and prejudices, difficulties in forming a "barrier-free" psychological environment.

Summarizing the above, we define the professional and personal readiness of a teacher as a complex integrative education, which meaningfully includes a pedagogical substructure (theoretical and practical readiness, including knowledge and practical skills related to the implementation of inclusive educational practice) and psychological substructure (formation of professionally important qualities of the teacher's personality, special abilities that contribute to the formation of polysubject interaction in an inclusive educational environment - personal readiness) [17].

Based on the theoretical analysis of scientific literature, we organized an experimental study aimed at identifying the level of formation of professional and personal readiness of teachers and the relationship between the level of formation of theoretical and practical readiness and the level of severity of psychological barriers.

Experimental research has shown the presence of both common, characteristic for teachers of both schools, features in the formation of professional and personal readiness and its components, and specific, due to the inclusive culture of a particular educational organization.

The first general trend was the presence of similar indicators in the ranking of psychological barriers among teachers of both schools: the most pronounced group of barriers (first rank place) are psychological and cognitive barriers (lack of formation or difficulties in transferring knowledge to inclusive educational practice) $(62 \%$ and $70 \%$, respectively).

Whereas the following rank positions differ: for example, the second ranking place among teachers at Municipal Budgetary Educational Institution Secondary School No. 21 is occupied by emotional barriers $(57 \%)$, among which the most pronounced is the barrier of mental tension $(66 \%)$ and the barrier of self-disbelief in the implementation of inclusive education (62\%). The third ranking place is given to communication barriers $(49 \%)$, among which teachers noted the presence of phonetic and linguistic barriers (51\%).

In turn, among teachers of Municipal Budgetary Educational Institution Secondary School No. 12, the second rank place is given to communicative barriers $(64 \%)$, among which the most pronounced are the semantic or semantic barrier (71\%) and linguistic $(68 \%)$. Teachers note that they experience the greatest difficulties in working with children 
with mental and autism spectrum disorders, especially in cases where the child has severe and moderate systemic speech underdevelopment or a specific speech disorder. In this case, children have pronounced limitations in the possibilities of oral communication and there is a need to use the means of alternative or augment communication, which most of the teachers do not know. In this regard, difficulties arise in building a dialogue interaction. In third place are emotional barriers (56\%) with the greatest severity, as among teachers at Municipal Budgetary Educational Institution Secondary School No. 21, the barrier of selfconfidence in the implementation of inclusive educational practice (71\%).

The next stage of the experimental work was the correlation of the indicators obtained in the study of barriers with the indicators of the study of theoretical and practical readiness.

Quantitative data allow us to note the following general trend: teachers of both schools have a level of practical readiness, which provides for the formation of skills (analytical, prognostic, design, organizational, communicative, reflexive; skills and labor actions provided for by the Teacher's Professional Standard, as well as skills related to the development and implementation of the adapted basic general educational program and the individual educational program of the child) is higher than the level of theoretical readiness (95\% and 92\% in Municipal Budgetary Educational Institution Secondary School No. 21 and $96 \%$ and $72 \%$ in Municipal Budgetary Educational Institution Secondary School No. 12).

This, in our opinion, is explained by the fact that the need to create adapted basic general education programs based on knowledge of the special educational needs of children of different nosological groups and special conditions due to these characteristics arose before the regulatory and legal framework appeared, regulating educational the route of a child with disabilities: Federal State Educational Standard for Primary General Education students with disabilities and Federal State Educational Standard for students with mental retardation (2016). Thus, with a significant lack of knowledge about the conditions for the implementation of the adapted basic general education programs of Primary General Eucation in accordance with the requirements of the Federal State Educational Standard of PGE for students with disabilities, teachers are involved in the development and implementation of the child's educational route in the form of adapted basic general education programs and individual educational programs. That is why, in our opinion, the indicators of the practical component of the readiness of teachers of both schools are higher than the indicators of the theoretical component.

At the same time, we see the presence of negative correlations between the following variables:

- between the indicators of teacher readiness and the severity of barriers: a low level of knowledge and skills formation in the field of inclusive education is associated with a high level of severity of psychological and cognitive barriers among teachers of both schools (70\% - the first rank place);

- between the formation of skills and the severity of barriers: a high level of formation of communicative skills among teachers of Municipal Budgetary Educational Institution Secondary School No. 21 is associated with a low level of severity of communication barriers (56\% - the third rank place).

Thus, a qualitative analysis of the quantitative indicators of the study of psychological barriers and the theoretical and practical readiness of teachers showed a pronounced relationship between these indicators of the professional and personal readiness of teachers. 


\section{Conclusions}

The conducted research allows us to conclude that the professional and personal readiness of teachers is a component of the inclusive culture of the personality of the teacher and the inclusive educational culture of the educational organization. A high level of knowledge and skills formation in the field of inclusive education (pedagogical readiness substructure), professionally important personality traits, among which we single out a special professional ability - to see and overcome psychological barriers (psychological readiness substructure) - ensure the effective functioning of an inclusive educational environment, the main content which is a semi-subject interaction based on the dialogue between the teacher and the student.

In general, it can be noted that the level of professional and personal readiness among teachers at Municipal Budgetary Educational Institution Secondary School No. 21 is higher than among teachers at Municipal Budgetary Educational Institution Secondary School No. 12, which, in our opinion, is due to the fact that Municipal Budgetary Educational Institution Secondary School No. 21 has a longer path of forming an inclusive culture and practice, has a higher level of resources (psychological, methodological, etc.).

\section{References}

1. S.V Alekhina, Inclusive Education: History and Modernity, p. 27-28. (Moskow: Pedagogical University, 2013)

2. S.V. Alekhina, M.N. Alekseeva, E.L. Agafonova, Readiness of teachers as the main factor in the success of the inclusive process in education. Psychological Science and Education, 16 (1), 83-92 (2011)

3. K.G. Bagdueva, I.A. Hajiyev, F.G. Hajiyeva, Inclusive culture of educational organization: theoretical and methodological aspects. The world of science, culture, education, 1 (62), 112-113 (2017)

4. Ye.V. Bondarevskaya, Pedagogical culture as a social and personal value, Pedagogy, 3, 37-43 (1999)

5. Booth T., M. Ainscoe, Indicators of inclusion, p. 7-9. (Moskow: CSIE, 2007)

6. I.V. Vachkov, A polysubjective approach to the interaction of subjects of an inclusive educational environment. Psychological and pedagogical foundations of inclusive education, p. 84-96 (Monography, Moskow: MSPPU, 2013)

7. I.V. Vachkov, Polysubject interaction in the educational environment. Psychology. Journal of the Higher School of Economics, 11 (2), 36-50 (2014)

8. T.P. Dmitrieva, Organizing the activities of an inclusion coordinator in an educational institution, p. 19-20. (Moskow, 2010)

9. V.Z. Cantor, About teacher training for inclusive education. Bulletin of Herzen University, 29-31 (2010)

10. E. Ketrish, V. Fedorov, N.Tretyakova, T. Andruhina, E. Shehetz, Readiness for Work Under Inclusive Education Conditions as Stage of Formation of Teacher's Inclusive Culture. Elementary Education Online, 4(18), 2109-2127 (2019)

11. Yu.A. Koroleva, The teacher's readiness to work with students with disabilities as a condition for the success of the inclusive process (based on the material of the Orenburg region), TOGIRRO Bulletin, 1, 296-299 (2013)

12. O.Yu. Litvintseva, Psychological safety of participants in an inclusive educational process, Scientific-methodical electronic journal "Concept", 12, 100-109 (2019) 
13. N. Pershina, M. Shamardina, N. Luzhbina. Readiness of teachers for inclusive education of children with disabilities, SHS Web of Conferences, 55:02005 DOI: $10.1051 /$ shsconf/20185502005 (2018)

14. V.A. Petrovsky, Personality in psychology: the paradigm of subjectivity, p. 297-320 (Monography, Rostov-on-don, 1996)

15. A.I. Polyansky, V.D. Martirosyan, Inclusive culture in the educational organization. Scientific works of the Moscow University for the Humanities, 1, 67-72 DOI: 10.17805 / trudy.2018.1.7 (2018)

16. E. Slusareva, A. Dontsov, M. Popova, Formation of professional readiness of teachers as a condition of realization of effective inclusive educational practice. International Conference on Man-Power-Law-Governance: Interdisciplinary Approaches (MPLGIA 2019), 408-413, DOI: 10.2991/mplg-ia-19.2019.74 (2019)

17. Ye.S. Slyusareva, Methodology of psychological diagnostics of pedagogues' readiness for implementation of inclusive educational practice. Vestnik of Kostroma State University. Series: Pedagogy. Psychology. Sociokinetics, 1, 104-111 (in Russ.), DOI 10.34216/2073-1426-2020-26-1-104-111 (2020)

18. O.V. Solovyova, Inclusive culture and ethics in educational organization. Methodological approaches to the implementation of inclusive processes in the higher education system: results and prospect,. p. 46-49 (Monography, Stavropol, 2019)

19. N.V. Starovoit, Inclusive culture of educational organization: approaches to understanding and formation. Scientific-methodical electronic journal "Concept", 8, 31-35 (2016)

20. E.S. Fominykh, Psychological barriers of participants in educational relations in an inclusive space. Scientific-methodical electronic journal "Concept", S, 23, 57-61 (2017)

21. T.V. Furyaeva, Social inclusion: theory and practice. Anthropology and Social Practice, p. 64-70 (Monography, Krasnoyarsk, 2017)

22. V.V. Khitryuk, Inclusive readiness as a stage in the formation of an inclusive teacher culture: a structural-level analysis. Bulletin of the Bryansk State University, 1-1, 80-84 (2012)

23. V.V. Khitryuk, Readiness of teachers to work in inclusive education, Bulletin of the Chuvash State Pedagogical University named after I.Ya. Yakovlev, 3 (79), 189-194 (2013)

24. I.M. Yakovleva. Professional and personal readiness of a teacher to work with children with disabilities. Bulletin of the Moscow State Regional University. Pedagogy, 4, 140 144 (2009) 